\title{
Congenital perineal defect with rectal duplication and extreme hypospadias - a rare association
}

\author{
Mrinal Arora ${ }^{*}$, Noor Ullah Zargar and Anurag Krishna
}

\begin{abstract}
Background: Congenital perineal hernia is an extremely rare entity with only 10 cases having been reported in literature. We report a newborn with exposed bowel loops coming out through a defect in the perineum to the right of the median raphe and propose the term perineoschisis for this abnormality. The exposed bowel loops were a sequestered segment of colon. The baby also had extreme perineal hypospadias and left undescended testis.

Case presentation: A term neonate, born of caesarean section, was noted at birth to have exposed bowel loops visible in the perineum. The bowel loops were not covered by any membrane. To avoid injury to the exposed bowel loops and setting in of infection, the baby was taken up for emergency surgery. At laparotomy, the bowel loops were traced from duodeno-jejunal junction to ileocecal junction and sigmoid colon and rectum. No loops were seen herniating outside from the abdomen through the perineum opening. The extruded bowel loops were sequestered and ending blindly close to the rectum. The sequestered bowel loops were excised completely and perineum reconstruction was done.

Conclusion: The extruded bowel loops would appear to be a form of colonic duplication with the duplicated colonic loops herniating outside through an opening in the perineum. Since the bowel loops were lying to the right of median raphe and were not covered by hernia sac or any other membrane we propose the term perineoschisis for this abnormality. The baby also had extreme hypospadias with a perineal meatus, bifid scrotum and penoscrotal transposition. This association of herniated duplicated colon with extreme hypospadias is hitherto unreported to the best of our knowledge.
\end{abstract}

Keywords: Perineoschisis, Congenital perineal hernia, Extreme hypospadias

\section{Background}

Congenital perineal hernia is an extremely rare entity with only 10 cases having been reported in the literature, of which two were reported in aborted fetuses [1-9]. In all earlier reported cases, the herniated bowel loops were covered either by skin or a peritoneal sac. In our case, since the exposed bowel loops were seen coming out through a defect in the perineum to the right of the median raphe, we propose the term perineoschisis which

\footnotetext{
*Correspondence: mrinalarora87@gmail.com

Pediatric Surgery, Max Smart Superspeciality Hospital, New Delhi 110017 India
}

would more appropriately describe this abnormality. The baby also had extreme perineal hypospadias and left undescended testis, an association not hitherto reported.

\section{Case presentation}

A term, newborn with a birth weight of $2.37 \mathrm{~kg}$, was born of caesarean section. At birth, the baby was noted to have exposed bowel loops herniating through an opening in the perineum. The antenatal scans had not mentioned any anomaly. The baby was referred to our hospital for management. On examination, bowel loops were visible in the perineum extruding through an opening to the right of the median raphe, not covered by overlying skin 
or any membrane (Fig 1). The anal opening along with the median raphe was deviated to the left. The baby also had severe hypospadias with a perineal meatus. There was complete penoscrotal transposition and bifid scrotum (Fig. 2). A patch of mucosa with a central pit was seen around the urinary meatus extending into the perineum raising the suspicion of vaginal tissue (Fig. 3). The right testis was present in the scrotum and the left gonad was palpable in the inguinal region.

Ultrasound scan showed normal kidneys. No mullerian structures were identified. Echocardiography was normal. Karyotyping showed a normal $46 \mathrm{XY}$ pattern.

To avoid injury to the exposed bowel loops and setting in of infection, the baby was taken up for emergency surgery. Bladder catheterization was done with a 6-Fr Foley catheter. The abdomen was opened through a pfannenstiel incision to get good access to the pelvic floor. The bowel loops were traced from the duodenojejunal junction through the ileocecal junction to the sigmoid colon and rectum. No bowel loops were seen herniating from the abdomen outside through the perineum. No defect was noted in the pelvic floor and there was no communication between the abdominal bowel loops and extruded bowel loops in the perineum. Both vas deferens were traced till the deep ring. No mullerian structures were seen in the pelvis. The bowel loops in the perineum were mobilized and traced upwards. There was no sharing of blood supply between the sequestered bowel and intra abdominal bowel loops. They were ending blindly with a close approximation to the postero-lateral wall of

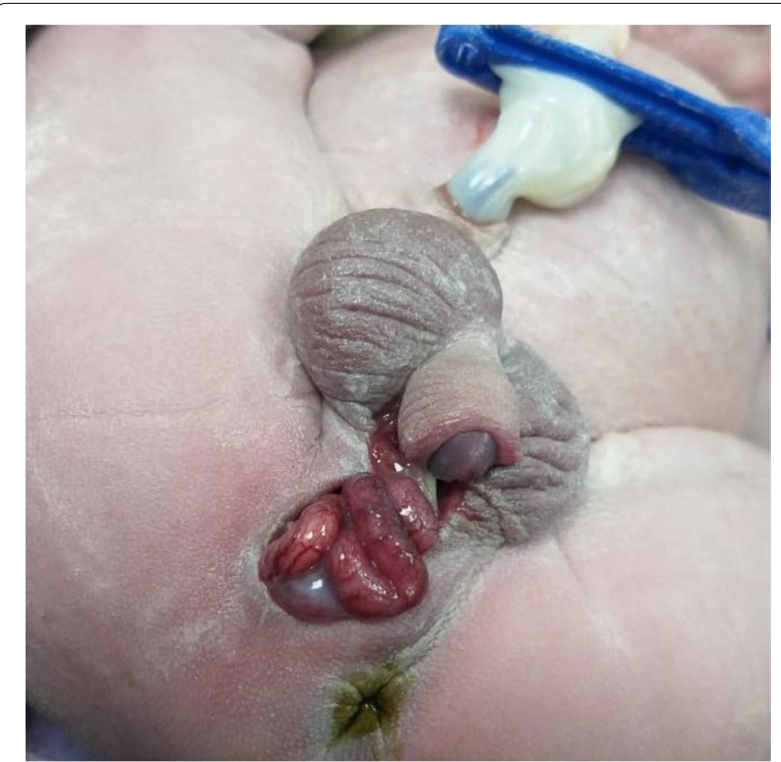

Fig. 1 Exposed bowel loops lying in the perineum to the right of midline with a normal anal orifice deviated towards the left

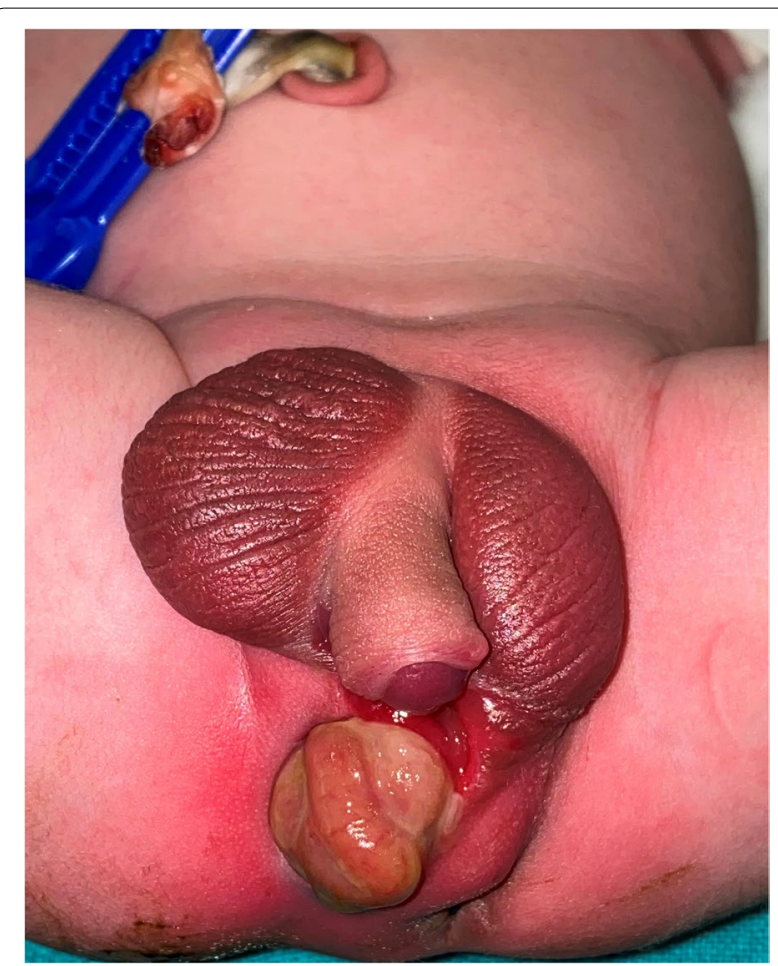

Fig. 2 Associated extreme hypospadias with complete penoscrotal transposition and bifid scrotum

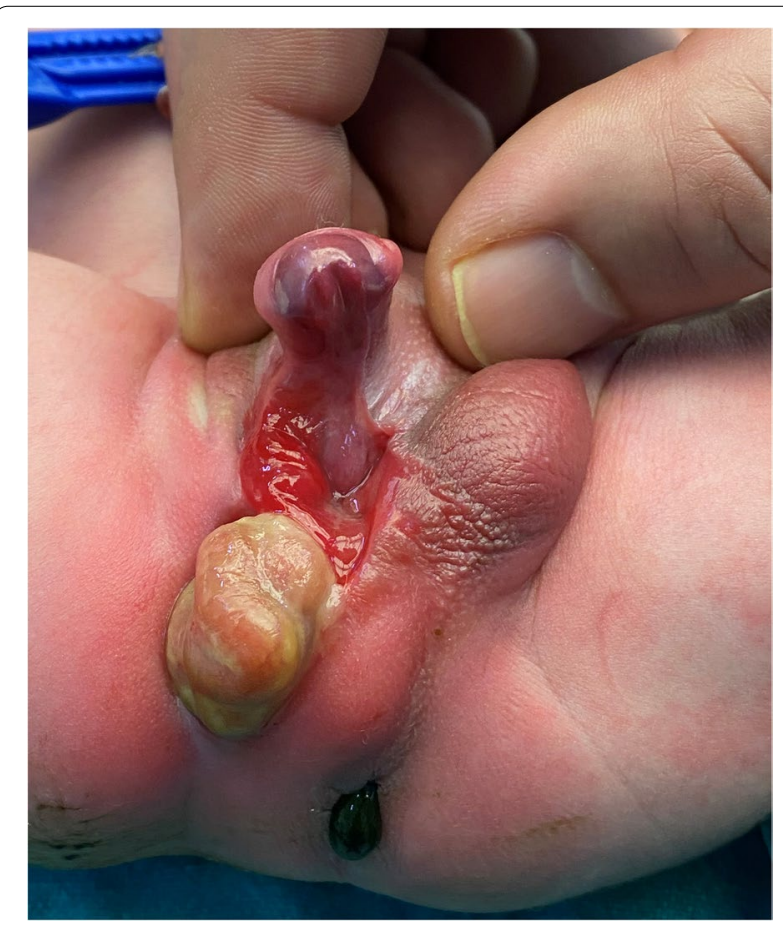

Fig. 3 Extreme perineal hypospadias, with a patch of mucosa with central pit seen around the urinary meatus raising the possibility of vaginal tissue 


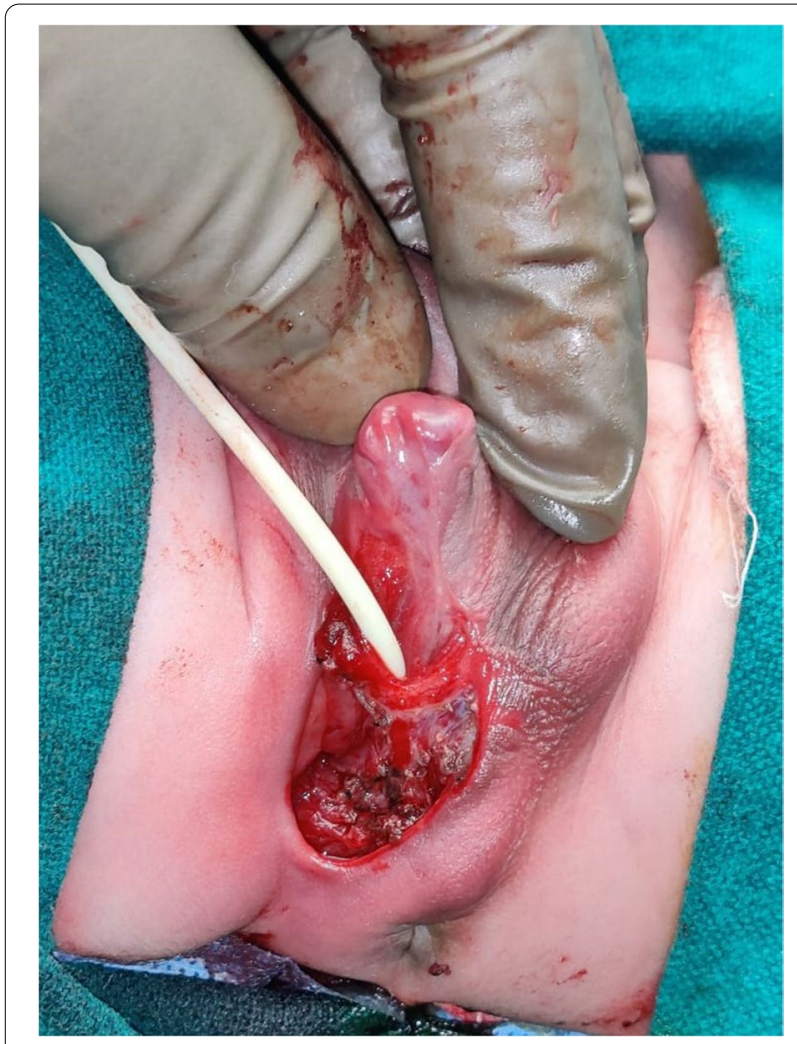

Fig. 4 Perineal defect-after excision of the sequestered bowel loops

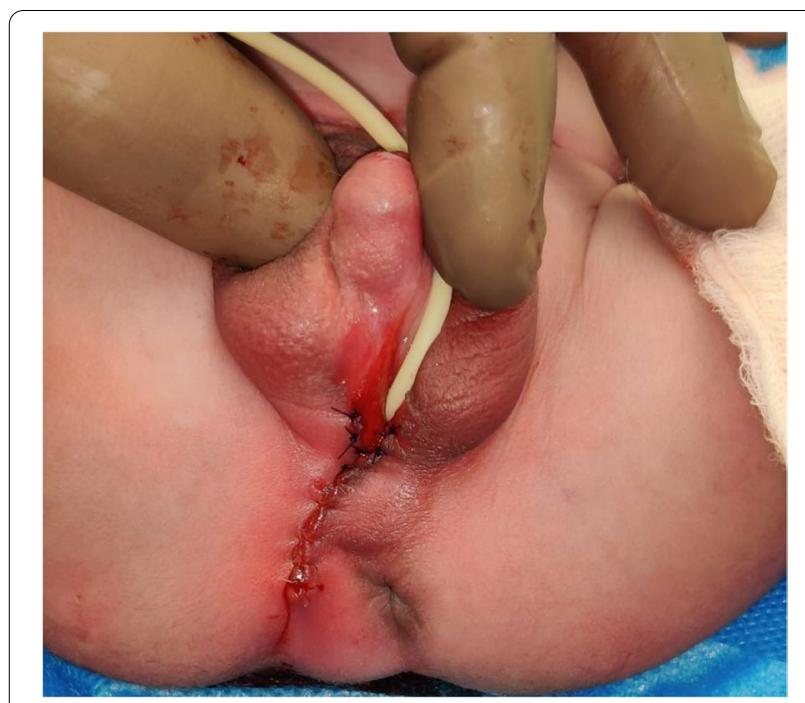

Fig. 5 Repaired perineum after excision of the bowel loops

the rectum. The sequestered bowel loops were excised and were taken cared of to avoid injury to the rectum. Muscles of the perineum were identified and the perineal defect was closed in layers (Figs. 4 and 5). After reconstruction, the median raphe and anal opening returned to midline position. The anus was normally located within the muscle complex. The mucosal patch close to the urinary meatus was also excised. Histology of the sequestered bowel showed it to be colonic tissue. The mucosal patch that was thought to be vaginal tissue also was colonic mucosa.

Postoperatively, the baby was fed from the third post operative day. At a follow-up visit after 6 months, the perineum is well healed and the baby is awaiting genital reconstruction.

\section{Discussion}

Perineal hernias are known by different names-ischiorectal hernia, pudendal hernia, posterior labial hernia, sub-pubic hernia, hernia of Douglas' pouch, vaginal hernia, and pelvic hernia [1]. These hernias develop as a result of weaknesses or defects during development in the musculature of the pelvic floor. They can be broadly classified as congenital or acquired hernia [10]. Congenital hernias develop due to the persistence of a cul-desac descending into the perineum in embryonic life [1]. Acquired perineal hernias are generally found in adults, after pelvic surgeries. Anatomically, they are classified as anterior-those that arise from defective urogenital diaphragm and are lying anterior to the paired superficial transverse perineal muscles, and posterior-which occur as a defect within the levator ani muscles constituting the pelvic diaphragm or through defects resulting from the failure of obturator internus and ileococcygeus muscles to join [11]. Congenital hernias are generally of the posterior type [12].

Most of the earlier reported cases had delayed presentation because the defect was the covered type. Our case was diagnosed on day one of life as the bowel loops were lying exposed in the perineum. The exposed bowel loops were not connected to the intestinal loops inside the abdomen and were ending blindly with a close approximation to the rectum. This would appear to be a form of colonic duplication with the duplicated colon loops extruding through the perineal defect. Since the perineal defect was to the right of the median raphe and the bowel loops were lying exposed, we propose the term perineoschisis to better describe this abnormality. The isolated patch of colonic mucosa around the urinary meatus in the perineum would suggest a failure of the transverse septum to clearly separate the urogenital sinus from the anorectum. The severe form of hypospadias with bifid scrotum, penoscrotal transposition, and left undescended testis raised the possibility of a disorder of sexual differentiation but the karyotyping results were normal 46XY. Perineal herniation of duplicated colonic 
loops associated with extreme hypospadias has not been reported in the literature to the best of our knowledge.

Different surgical approaches have been described for the repair of such defects-abdominal, perineal, and combined abdominoperineal [13]. We began with the abdominal approach but could not find any bowel loops herniating outside through the pelvic floor. Hence, we mobilized the exposed bowel in the perineum and traced it upwards to its attachment to the lateral rectal wall. The combined approach though better since it allows better delineation of the anatomy, it adds to the overall morbidity. The perineum was repaired in layers with primary suturing. Perineal repair with the use of flaps and mesh has been reported in the literature, but they are generally described in adults [12].

\section{Conclusion}

This is a very rare case of congenital perineal herniation of the bowel loops, lying exposed in the perineum requiring emergency exploration. The exposed loops were sequestered colonic loops herniating through a perineal defect and ending blindly close to the rectum. We believe a combined abdomino-perineal approach may be best to repair such abnormalities. The abnormality is better described by the term perineoschisis, rather than congenital perineal hernia.

\section{Acknowledgements}

Not applicable.

\section{Authors' contributions}

MA has made substantial contribution to the conception and design of work and drafted the work. NZ reviewed the work and final draft was approved by AK. The manuscript has been read and approved by all the authors and each author believes that the manuscript represents honest work.

\section{Funding}

Nil.

\section{Availability of data and materials}

Data sharing is not applicable to this article as no data sets were generated or analyzed.

\section{Declarations}

\section{Ethics approval and consent to participate}

The authors certify that they have obtained all appropriate patient consent forms. In the form, the patient's parent has given his consent for his images and other clinical information to be reported in the journal. The patient's parent understands that his names and initials will not be published and due efforts will be made to conceal their identity, but anonymity cannot be guaranteed. This manuscript has got ethical approval by the hospital committee.

\section{Consent for publication}

Written informed consent was obtained from the patient for publication of this case and any accompanying images.

\section{Competing interests}

The authors declare that they have no competing interests.

Received: 12 July 2021 Accepted: 13 November 2021

Published online: 04 March 2022

\section{References}

1. Mohta A, Bhargava SK. Congenital perineal hernia: report of a case. Surg Today. 2004;84:630-1.

2. Cali RL, Pitsch RM, Blatchford GJ, Thorson A, Christensen MA. Rare pelvic floor hernias. Report of a case and review of the literature. Dis Colon Rectum. 1992;35:604-12.

3. Moschowitz AJ. Perineal hernia. Surg Gynecol Obstet. 1918;26:514.

4. Doig CM, Nixon HH. Pelvic hernias in children. J Pediatr Surg. 1972;7(1):44-7.

5. Fiirgard B, Agertoft A. Internal Richter's hernia due to congenital peritoneal defect. Acta Chir Scand. 1988;154:537.

6. Hubbard AM, Egelhoff JC. Posterior perineal hernia presenting in infancy as a gluteal mass. Pediatr Radiol. 1989;19:246.

7. Kravarusic D, Swartz M, Freud E. Perineal hernias in children: case report and review of the literature. Afr J Paediatr Surg. 2012;9(2):172-5.

8. Bianca S, Bartoloni G, Barrano B, Boemi G, Barone C, Cataliotti A, et al. Congenital perineal hernia in a fetus with $\mathrm{X}$ monosomy. Congenit Anom (Kyoto). 2009:49(4):279.

9. Steffenson TS, Opitz JM, Gilbert-Barness E. Congenital perineal hernia in a fetus with trisomy 18. Fetal Pediatr Pathol. 2009:28(2):95-9.

10. Kann BR. Perineal hernias. J Long Term Eff Med Implants. 2010;20(2):149-57.

11. Stamatiou D, Skandalakis JE, Skandalakis $L J$, Mirilas P. Perineal hernia: surgical anatomy, embryology, and technique of repair. Am Surg. 2010;76(5):474-9.

12. Watanobe I, Miyano S, Machida M, Sugo H. Primary anterior perineal hernia: a case report and review of the literature. Asian J Endosc Surg. 2020;13:600-4.

13. Ntagandaa E, Niyongombwaa I, St-Louisb E, Emilb S, Labergeb JM. Congenital perineal hernia. J Pediatr Surg Case Rep. 2018;32:46-8.

\section{Publisher's Note}

Springer Nature remains neutral with regard to jurisdictional claims in published maps and institutional affiliations.

\section{Submit your manuscript to a SpringerOpen ${ }^{\odot}$ journal and benefit from:}

- Convenient online submission

- Rigorous peer review

- Open access: articles freely available online

- High visibility within the field

- Retaining the copyright to your article

Submit your next manuscript at $\boldsymbol{\nabla}$ springeropen.com 